\title{
Biological control of garlic (Allium) white rot disease using antagonistic fungi-based bioformulations
}

\author{
Razak Mahdizadehnaraghi ${ }^{1}$, Asghar Heydari ${ }^{2 *}$, Hamid Reza Zamanizadeh ${ }^{1}$, \\ Saeed Rezaee ${ }^{1}$, Jafar Nikan²
}

\author{
${ }^{1}$ Department of Plant Pathology, College of Agriculture and Natural Resources, Science and Research Branch, \\ Islamic Azad University, P.O. Box 14515/775, Tehran, Iran \\ ${ }^{2}$ Plant Disease Research Department, Iranian Research Institute of Plant Protection, P.O. Box 1452, Tehran 19395, Iran
}

Received: November 16, 2014

Accepted: March 25, 2015

\begin{abstract}
White rot disease caused by Sclerotium cepivorum is a major yield reducing fungal disease of garlic found throughout the world, including Iran. The use of chemical fungicides is the most common control method for the disease at the present time. This control measure is costly, contaminates the environment, and harms non-target organisms. Moreover, since the pathogen is soil-borne, chemical control strategy is not quite effective against the disease. In this study, we tried to develop and prepare some new bioformulations based on three antagonistic fungal species: Trichoderma harzianum, T. asperellum, and Talaromyces flavus. Six isolates of the abovementioned fungi were used along with the organic and inorganic carriers, rice bran and talc, to develop twelve new bioformulations. The effectiveness of the bioformulations were then evaluated in the control of garlic white rot disease in the greenhouse conditions in comparison with the healthy control, infected control, and the commonly used fungicide Carbendazim. The design of the experiment was completely randomised. There were 15 treatments each, with four replicates. The results of the greenhouse experiments indicated that almost all the developed bioformulations resulted in significant reductions ( 34.50 to $64.50 \%$ ) in the incidence of white rot disease. In general, bioformulations which contained the organic carrier (rice bran) performed more effectively than those that contained the inorganic carrier (talc). Bioformulations which contained an organic carrier (rice bran) were as effective as the fungicide Carbendazim.
\end{abstract}

Key words: Allium white rot, bioformulation, biological control, garlic, rice bran, talc

\section{Introduction}

Continuous and long-term use of chemical pesticides in agriculture has led to: toxic residues, the appearance of resistant pests and pathogens, environmental contaminations, and negative impacts on non-target organisms including humans (Cook and Baker 1988). Biological control using microbial antagonists has been shown to be a suitable ecologically-friendly candidate which could replace chemical pesticides (Cook and Baker 1988). Different fungal and bacterial antagonists have proved to be potential biocontrol agents for controlling many plant pathogenic fungi (Metcalf et al. 2004; Heydari and Pessarakli 2010; Sharifi et al. 2010; Francisco et al. 2011; Kakvan et al. 2013; Naraghi et al. 2013; Blaszczyk et al. 2014; Khiyami et al. 2014). In this regard, different species of Trichoderma have been successfully used and have produced promising results. For example, in a recent study, a different Trichoderma species was used for controlling sugar beet seedling damping-off disease (Kakvan et al. 2013). In another recent study, isolates of Trichoderma spp. were successfully used to control Botrytis cinerea on strawberry (Naeimi and Zare 2014).

*Corresponding address:

heydari1384@yahoo.com
Talaromyces flavus is also a fungal antagonist which has been used in the biological control of several plant pathogenic fungi. Talaromyces flavus has been used on Verticillium dahliae which is the causal agent of wilt disease on several plants (Naraghi et al. 2006; Naraghi et al. 2010; Naraghi et al. 2013). This antagonistic fungus has also been used in a recent study conducted by Kakvan et al. (2013) for controlling the damping-off disease of sugar beet, and has produced promising results.

The majority of antagonistic microorganisms, including fungi, perform well in controlled environmental conditions but fail to do so in the field. This failure is due to several reasons including inappropriate application methods. One of the most important reasons for the failure of fungal antagonists in the field may been related to the lack of the use of a proper formulation. The most practical method for the application of biocontrol agents in the field is to develop and prepare powdery formulations for farmers to use them as seed treatment, particularly for controlling seed and root diseases. Studies have shown that the efficacy of some microbial antagonists in biological control of different plant diseases has been preserved after they have been mixed with organic and inor- 
ganic carriers (Heydari and Pessarakli 2010; Kakvan et al. 2013; Samavat et al. 2014).

Garlic is an important nutritional crop grown in many countries around the world, including Iran (Clarkson et al. 2002; Davis et al. 2007; Mahdizadehnaraghi et al. 2007; Bakonyi et al. 2011). Like many other crop plants, garlic is also susceptible to several plant pathogenic agents including soil-born fungi (Clarkson et al. 2002; Davis et al. 2007; Francisco et al. 2011). White rot is one of the most important garlic diseases in the world, including Iran (Clarkson et al. 2002; Keller et al. 2005; Mahdizadehnaraghi et al. 2007). The causal agent of the disease is Sclerotium cepivorum which is a fungal pathogen and usually produces sclerotia in the soil (Ulacio-Osorio et al. 2006). The produced sclerotia remain in the soil and begin to germinate in response to plant root exudates. The sclerotia penetrate their host plant causing white rot disease (Davis et al. 2007). The use of chemical fungicides as seed treatment is the most common strategy for controlling this disease in the field. Most of the time, this strategy is not effective due to the long application time, and the appearance of resistant races of the pathogen (Heydari and Passarakli 2010). In addition, the high production cost of the chemical fungicides and the negative impacts on nontarget organisms must be considered.

In order to evaluate the efficacy of fungal antagonists when mixed with carriers, this study was conducted and executed to develop some new bioformulations using three fungal antagonists (Trichoderma harzianum, T. asperellum, and T. flavus) and an organic and an inorganic carrier (rice bran and talc). Their effects of the new bioformulations on garlic white rot disease in the greenhouse conditions were investigated.

\section{Materials and Methods}

\section{Isolation of Sclerotium cepivorum from garlic fields}

During the spring of 2014, the garlic fields in the province of Hamedan, Iran were surveyed. Diseased plants showing white rot symptoms were collected and transferred to the laboratory so that the pathogenic agents could be isolated. Diseased samples were processed by cutting, removing, surface sterilising and culturing diseased pieces of stems and bulbs on Potato Dextrose Agar (PDA) cul- ture medium. The grown fungal colonies were then purified and were identified using the standard identification keys of Barnett and Hunter (1998). Based on the abovementioned experiments, five isolates of S. cepivorum were identified.

The pathogenicity test (Koch postulate) was also conducted and performed to confirm the role of the isolated fungus in disease occurrence and symptom appearance.

The test was performed on five isolates of S. cepivorum in a greenhouse experiment with five treatments each with four replicates. A replicate consisted of a plastic pot containing $2 \mathrm{~kg}$ of garlic-field, pasteurised soil pre-inoculated with S. cepivorum and sown with three garlic seeds (bulbs). After the appearance of symptoms on garlic plants, the pathogenic agent was re-isolated from the infected tissues, identified as described in the above sections, and evaluated for pathogenicity according to the respective disease percent induction (Mahdizadehnaraghi et al. 2007). Based on the above experiments, the most pathogenic isolate of S. cepivorum was selected to be used for the rest of the study.

\section{Preparation of antagonistic fungal isolates}

Isolates of three fungal antagonists including T. flavus, T. harzianum, and T. asperellum were obtained from the research laboratory's microbial collection of beneficial microorganisms, of the Iranian Research Institute of Plant Protection. In 2013, these isolates were isolated from the soil of garlic and potato fields located in the province of Hamedan, Iran. The antagonistic activities of the isolates against some fungal pathogens, including S. cepivorum, were previously evaluated and approved in in vitro conditions in the above-mentioned laboratory (unpublished data). The antagonistic fungal isolates used in the study and their characteristics are presented in table 1.

\section{Development and preparation of bioformulations}

Twelve bioformulations were prepared using six isolates of the above-mentioned fungal antagonists and the organic and inorganic carriers - rice bran and talc. The powdery compounds of the carriers were selected based on their use in previous studies (Kakvan et al. 2013; Samavat et al. 2014). They were steam-sterilised at $121^{\circ} \mathrm{C}$ for $30 \mathrm{~min}$, and dried aseptically in glass trays before use.

Table 1. Characteristics of antagonistic fungal isolates used in the study

\begin{tabular}{|c|c|c|c|c|c|}
\hline No. & Isolate identity & Isolate code & Isolation host & Isolation location & Isolation time \\
\hline 1 & Trichoderma harzianum (isolate 1) & T.h-1 & garlic & Hamedan province & spring 2013 \\
\hline 2 & T. harzianum (isolate 2) & T.h-2 & garlic & Hamedan province & spring 2013 \\
\hline 3 & T. asperellum (isolate 1) & T.a-1 & potato & Hamedan province & summer 2013 \\
\hline 4 & T. asperellum (isolate 2) & T.a-2 & potato & Hamedan province & fall 3013 \\
\hline 5 & Talaromyces flavus (isolate 1) & T.f-1 & garlic & Hamedan province & fall 2013 \\
\hline 6 & T. flavus (isolate 2) & T.f-2 & garlic & Hamedan province & fall 2013 \\
\hline
\end{tabular}


Table 2. Developed bioformulations and their ingredients

\begin{tabular}{|c|c|c|}
\hline No. & Bioformulation code & Bioformulation description (ingredient) \\
\hline 1 & R.B-T.h-1 & $10 \mathrm{ml}$ spore suspension of Trichoderma harzianum $-1+50 \mathrm{~g}$ of rice bran carrier \\
\hline 2 & R.B-T.h-2 & $10 \mathrm{ml}$ spore suspension of $T$. harzianum-2 $+50 \mathrm{~g}$ of rice bran carrier \\
\hline 3 & R.B-T.a-1 & $10 \mathrm{ml}$ spore suspension of T. asperellum $-1+50 \mathrm{~g}$ of rice bran carrier \\
\hline 4 & R.B-T.a-2 & $10 \mathrm{ml}$ spore suspension of T. asperellum $-2+50 \mathrm{~g}$ of rice bran carrier \\
\hline 5 & R.B-T.f-1 & $10 \mathrm{ml}$ spore suspension of Talaromyces flavus $-1+50 \mathrm{~g}$ of rice bran carrier \\
\hline 6 & R.B-T.f-2 & $10 \mathrm{ml}$ spore suspension of $T$. flavus $-2+50 \mathrm{~g}$ of rice bran carrier \\
\hline 7 & Talc-T.h-1 & $10 \mathrm{ml}$ spore suspension of Trichoderma harzianum-1 + $50 \mathrm{~g}$ of talc carrier \\
\hline 8 & Talc-T.h-2 & $10 \mathrm{ml}$ spore suspension of T. harzianum $-2+50 \mathrm{~g}$ of talc carrier \\
\hline 9 & Talc-T.a-1 & $10 \mathrm{ml}$ spore suspension of T. asperellum $-1+50 \mathrm{~g}$ of talc carrie \\
\hline 10 & Talc-T.a-2 & $10 \mathrm{ml}$ spore suspension of T. asperellum-2 + $50 \mathrm{~g}$ of talc carrie \\
\hline 11 & Talc-T.f-1 & $10 \mathrm{ml}$ spore suspension of Talaromyces flavus $-1+50 \mathrm{~g}$ of talc carrier \\
\hline 12 & Talc-T.f-2 & $10 \mathrm{ml}$ spore suspension of $T$. flavus $-2+50 \mathrm{~g}$ of talc carrier \\
\hline
\end{tabular}

The fungal isolates were first grown on PDA culture medium for purification and were then incubated for about three weeks for sporulation. The spores in the Petri plates were washed out by adding $10 \mathrm{ml}$ of distilled water to each plate. A spore suspension of each fungal isolate was prepared at $10^{7}$ spore $\cdot \mathrm{ml}^{-1}$ using a hemocytometer.

For preparation of the bioformulations, $10 \mathrm{ml}$ of each fungal spore suspension was added to a plastic bag containing $50 \mathrm{~g}$ of each carrier. The bags were then placed in an incubator at $30^{\circ} \mathrm{C}$ for three weeks until the fungi covered the surface of the carriers. The contents of the bags were then emptied and dried out in the laboratory and were used for seed treatment. For seed treatment, $5 \mathrm{~g}$ of each bioformulation was mixed with $15 \mathrm{ml}$ of distilled water, in a glass tray. This combination was used for the treatment of $100 \mathrm{~g}$ of garlic seed bulbs. The coating and treating of seeds was performed by rolling the garlic bulbs in the bioformulations for $10 \mathrm{~min}$. The bulbs were then allowed to dry for $60 \mathrm{~min}$. As a result of the above experiments, 12 bioformulations were developed and prepared using antagonistic fungal isolates and organic and inorganic carriers. A list of developed bioformulations and their specifications are presented in table 2 .

\section{Greenhouse experiments}

The greenhouse experiments were conducted with a completely randomised design (CRD) with 15 treatments (12 bioformulations, fungicide, infected control, and healthy control) each with four replicates. A replicate consisted of a plastic pot containing $2 \mathrm{~kg}$ of pasteurised garlic field soil pre-inoculated with S. cepivorum; and three garlic bulbs treated (coated) with each powdery bioformulation. The effectiveness of different bioformulations was determined 60 days after sowing by examining and indexing the white rot disease symptoms. The scale used was a $1-5$ standard indexing scale where 1 means - no disease, 2 means $-1-10 \%$ disease, 3 means $-11-25 \%$ disease, 4 means - 26-50\% disease, and 5 means - more than $50 \%$ disease (Entwistle 1990). The disease index was compared in different treatments to determine the efficacy of different bioformulations in controlling white rot disease. In addition to the disease index, the incidence of white rot disease was also calculated based on the disease index.

\section{Statistical analysis}

Data obtained in the experiments were first subjected to analysis of variance (ANOVA). The means were then compared using the Duncan Multiple Range Test with Statistical Analysis System (SAS) software version 9.0.

\section{Results}

The results of this study are presented in figures 1 and 2 as graphs. The results of the garlic white rot disease index evaluation in different treatments and their statistical comparison can be seen in figure 1. In the greenhouse study shown in figure 1, it can be seen that all bioformulations developed based on the rice bran organic carrier and all six isolates of antagonistic fungi, reduced the disease index of white rot significantly - in comparison with the infected (positive) control. Among this bioformulations, R.B-T.h-1 was the most effective followed by R.B-T.h-2 and R.B-T.a-2, respectively (Fig. 1). Although the remaining three bioformulations performed less effectively, they still reduced the disease incidence significantly compared to the infected control (Fig. 1). 


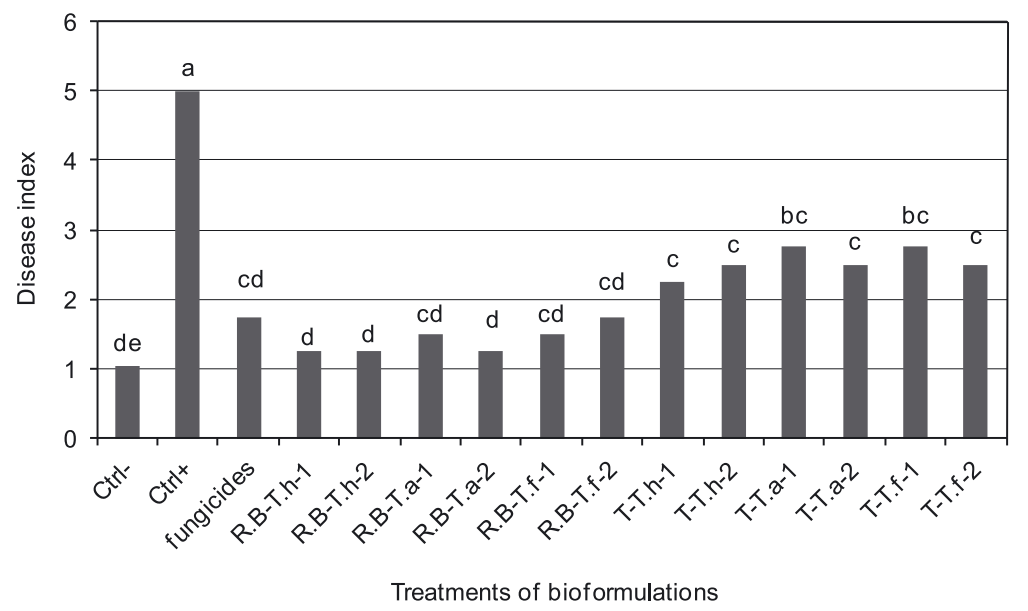

Fig. 1. Disease index of garlic white rot in different treatments of the greenhouse experiment: Ctrl- - negative control (without fungal pathogen and no bioformulation); Ctrl+- positive control (with fungal pathogen and no bioformulation); R.B-T.h - bioformulations containing rice bran and isolate of Trichoderma harzianum; R.B-T.a - rice bran and isolate of Trichoderma asperellum; R.B-T.f - rice bran and isolate of Trichoderma flavus; T-T.h - talc and isolate of T. harzianum; T-T.a - talc and isolate of T. asperellum; T-T.f - talc and isolate of $T$. flavus. The small letters show the level of statistical differences in different treatments

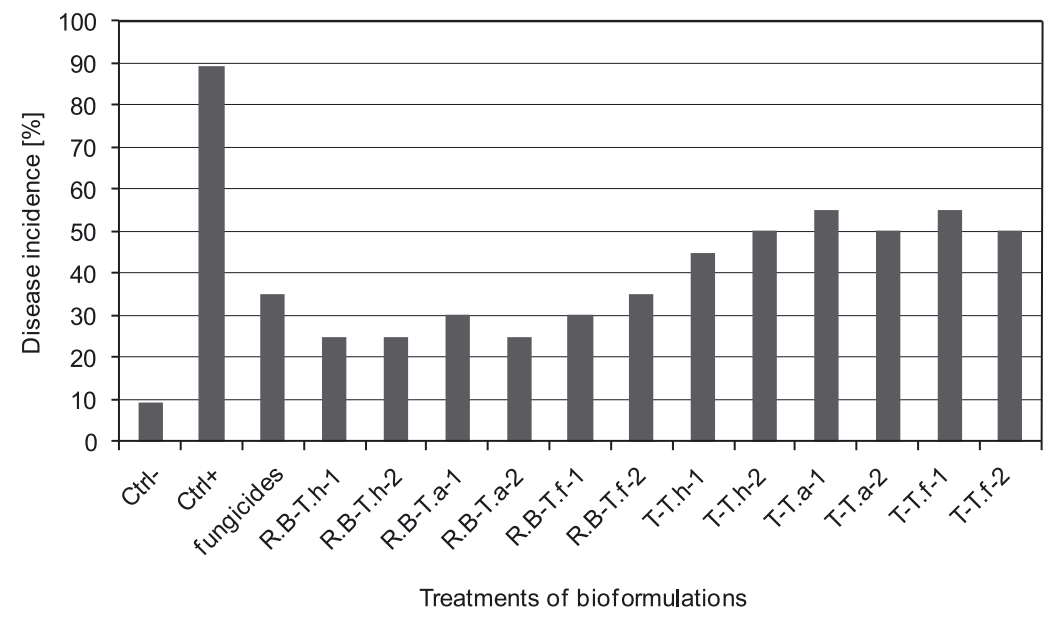

Fig. 2. Disease incidence of garlic white rot in different treatments of the greenhouse experiment; the explanations - see figure 1

Figure 2 indicates the incidence of garlic white rot disease which appears more evident. The disease incidence was calculated based on the disease index; in the form of disease percent in different treatments. Corresponding to the disease index, the incidence of white rot was also reduced by the bioformulations (Fig. 2). The highest reduction in disease incidence was achieved by R.B-T.h-1 as $64.50 \%$. In addition to the developed bioformulations, the fungicide Carbendazim also significantly reduced the index and incidence of garlic white rot compared to the infected control. The fungicide was not more effective than the bioformulations and was placed in the same statistical group (Fig. 2).

As the results presented in figures 1 and 2 indicate, in contrast to the rice bran-based bioformulations, those bioformulations developed using the talc inorganic carrier were less effective statistically than the chemical fungicide. However the performance of the six bioformulations containing the talc carrier and six isolates of fungal antagonists in the reduction of garlic white rot disease was also significant in comparison with the infected control (Figs. 1 and 2).

\section{Discussion}

The overall results of this study indicate that antagonistic fungi including T. harzianum, T. asperellum, and T. flavus in combination with organic and inorganic carriers can be used for the development of effective powdery bioformulations. The application of such bioformulations is used as seed (bulb) treatment for controlling garlic white rot which is one of the most important fungal diseases anywhere garlic is cultivated.

In this study, we developed 12 bioformulations using the above-mentioned fungal antagonists using rice bran and talc as the carriers. We evaluated them in greenhouse conditions against Allium white rot disease caused by S. cepivorum. Some isolates of Trichoderma were used in our study, because this antagonistic fungus has effectively been used in the control and management of different plant diseases in the previous studies (Francisco et al. 2011; El-Hassan et al. 2013; Kakvan et al. 2013; Naeimi and Zare 2014). In addition to the Trichoderma fungal antagonist, we also used two isolates of T. flavus for the development of our bioformulations. This fungus has 
also been used in several recent studies for the biological control of various plant pathogens (Naraghi et al. 2006; Naraghi et al. 2010; Kakvan et al. 2013; Naraghi et al. 2013). In the present study, we used the organic and inorganic carriers, rice bran and talc, for the developing our bioformulations. These carriers have commonly been used in previous studies for the development and preparation of various bioformulations (Naraghi et al. 2006; Kakvan et al. 2013; Samavat et al. 2014).

We developed and prepared the above-mentioned bioformulations for the biological control of white rot disease caused by S. cepivorum. White rot is one of the most important and damaging diseases of garlic wherever it is cultivated (Mahdizadehnaraghi et al. 2007; Bakonyi et al. 2011). Presently, the most common strategy for the control of this disease is the use of chemical fungicides though fungicides are not usually effective due to the soil-born nature of the causal agent. The negative impact of the chemical fungicides on the non-target organisms should also be considered (Cook and Baker 1988; Heydari and Naraghi 2014). In this study, we tried to introduce a nonchemical control method for this important disease.

The developed bioformultions were evaluated in the greenhouse for the reduction of white rot disease on garlic plants. According to the obtained results, almost all bioformulations performed effectively, reduced the disease. The effectiveness of rice bran-based bioformulations was higher than those containing talc. The higher effectiveness of rice bran is probably due to its organic nature, as has been shown in previous studies (Naraghi et al. 2006; Kakvan et al. 2013; Samavat et al. 2014). Among the antagonistic fungal isolates used in the present study, T. harzianum isolates performed more effectively. This is perhaps related to the isolation host and the genetic structure and variation among different fungal isolates.

The results of this study indicate that use of antagonistic fungi such as Trichoderma and Talaromyces in combination with organic and inorganic carriers such as rice bran and talc, can result in the development of effective bioformulations for controlling garlic white rot disease in greenhouse conditions. It is important to mention, that the developed bioformulations performed well and effectively in the greenhouse, but they may not perform as well in field conditions due to presence of some uncontrollable factors such as environmental conditions. However, the obtained results of the present study may have a practical application in the management of white rot which is a major disease of garlic in Iran, and can lead to yield increases, reduction in chemical fungicides applications, and protection of agricultural and environmental resources. The use of non-chemical strategies such as biological control methods for the management of plant diseases like garlic white rot, can be an important step toward a sustainable agricultural system.

\section{References}

Bakonyi J., Vajna L., Szeredi A., Tímár E., Kovács G.M., Csősz M., Varga A. 2011. First report of Sclerotium cepivorum causing white rot of garlic in Hungary. New Disease Reports 23: 5.
Barnett H.L., Hunter B. 1998. Illustrated Genera of Imperfect Fungi. 4th ed. American Phytopathological Society, St. Paul Minnesota, USA, 218 pp.

Blaszczyk L., Siwulski M., Sobieralski K., Lisiecka J., Jędryczka M. 2014. Trichoderma spp. - application and prospects for use in organic farming and industry. Journal of Plant Protection Research 54 (4): 309-317.

Clarkson J.P., Payne T., Mead A., Whipps J. 2002. Selection of fungal biological control agents of Sclerotium cepivorum for control of white rot by sclerotial degradation in UK soil. Plant Pathology 51 (6): 735-745.

Cook R.J., Baker K.F. 1988. The Nature and Practice of Biological Control of Plant Pathogens. American Phytopathological Society, St. Paul Minnesota, USA, 539 pp.

Davis R.M., Hao J.J., Romberg M.K., Nunez J.J., Smith R.F. 2007. Efficacy of germination stimulants of sclerotia of Sclerotium cepivorum for management of white rot of garlic. Plant Disease 91 (2): 204-208.

El-Hassan S.A., Gowen S.R., Pembroke B. 2013. Use of Trichoderma hamatum for biocontrol of lentil vascular wilt disease: efficacy, mechanisms of interaction and future prospects. Journal of Plant Protection Research 53 (1): 12-26.

Entwistle A.R. 1990. Allium white rot and its control. Soil Use and Management 6 (4): 201-209.

Francisco D.H., Angelica M.P., Gabriel M., Melchor C.S., Raul R., Cristobal N., Francisco C.R. 2011. In vitro antagonist action of Trichoderma strains against Sclerotium sclerotiorum and Sclerotium cepivorum. American Journal of Agriculture Biology Science 6 (3): 410-417.

Heydari A., Pessarakli M. 2010. A review on biological control of fungal plant pathogens using microbial antagonists. Journal of Biology Science 10 (4): 272-290.

Heydari A., Naraghi L. 2014. Application of antagonistic bacteria for the promotion of cotton seedlings growth characteristics. International Journal of Agriculture Crop Science 7 (13): 1267-1273.

Kakvan N., Heydari A., Zamanizadeh H.R., Rezaee S., Nraghi L. 2013. Development of new bioformulations using Trichoderma and Talaromyces fungal antagonists for biological control of sugar beet damping-off disease. Crop Protection 53 (1): 80-84.

Keller E.R.J., Senula A., Dreiling M. 2005. Gene banking of vegetative propagated medicinal plants - two cases: Allium and Mentha. Acta Horticulturae 676: 103-109.

Khiyami M.A., Omar M.R., Abd-Elsalam K., El-Hady Aly A. 2014. Bacillus-based biological control of cotton seedling disease complex. Journal of Plant Protection Research 54 (4): 340-348.

Mahdizadehnaraghi R., Zafari D., Zamanizadeh H., Arjmandian A. 2007. Identification and distribution of the important fungal disease agents on garlic in Hamedan province. Iranian Journal of Agriculture Results 3: 1735-1746.

Metcalf D.A., Dennis J.J.C., Wilson C.R. 2004. Effect of inoculum density of Sclerotium cepivorum on the ability of Trichoderma koningii to suppress white rot of onion. Plant Disease 88 (3): 287-291.

Naeimi Sh., Zare R. 2014. Evaluation of indigenous Trichoderma spp. isolates in biological control of Botrytis cinerea the causal agent of strawberry gray mold disease. Biocontrol in Plant Protection 1 (2): 55-74. (in Persian with English summary) 
Naraghi L., Heydari A., Ershad D. 2006. Sporulation and survival of Talaromyces flavus on different plant material residues for biological control of cotton wilt caused by Verticillium dahliae. Iranian Journal of Plant Pathology 42 (3): 381-397.

Naraghi L., Heydari A., Rezaee S., Razavi M., Mahmoodi Khaledi E. 2010. Biological control of tomato Verticillium wilt disease by Talaromyces flavus. Journal of Plant Protection Research 50 (3): 341-346.

Naraghi L., Heydari A., Rezaee S., Razavi M. 2013. Study on some antagonistic mechanisms of Talaromyces flavus against Verticillium dahliae and Verticillium albo-atrum, the causal agents of wilt disease in several important crops. Biocontrol in Plant Protection 1 (1): 13-28.
Ulacio-Osorio D., Zavaleta-Mejía E., Martínez-Garza A., Pedroza-Sandoval A. 2006. Strategies for management of Sclerotium cepivorum Berk. in garlic. Journal of Plant Pathology 88 (3): 253-258.

Samavat S., Heydari A., Zamanizadeh H.R., Rezaee S., Alizadeh Aliabadi A. 2014. A comparison between Pseudomonas aureofaciens (chlororaphis) and P. fluorescens in biological control of cotton seedling damping-off disease. Journal of Plant Protection Research 54 (2): 115-121.

Sharifi R., Ahmadzadeh M., Talebi-Jahromi K. 2010. Pyoverdine production in Pseudomonas fluorescens UTPF5 and its association with suppression of common bean damping off caused by Rhizoctonia solani (Kühn). Journal of Plant Protection Research 50 (1): 72-78. 